\title{
Prevalence of anemia and its determinants in urban school-going children of Mumbai
}

\section{Rupali V. Sabale, Shobha S. Kowli, Padmaja H. Chowdary}

Department of Community Medicine, K J Somaiya Medical College, Sion, Mumbai, Maharashtra, India

Address for the Correspondence:

Dr. Rupali V. Sabale,

E-6, 3-13, Nandanvan CHS, Jui Nagar, Sector 25,

Navi Mumbai - 400 705, Maharashtra India.

E-mail: rupali.kajrolkar@ rediffmail.com

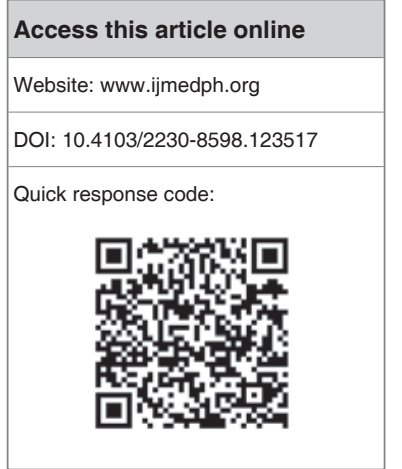

Context: WHO estimates that around two billion people are anemic with approximately $50 \%$ of all anemia attributable to iron deficiency. Weekly Iron and Folic Acid Supplementation Program is implemented in school, in various countries to reduce prevalence of anemia in adolescents. Aims: To find out baseline prevalence of anemia and its determinants in urban school-going children of Mumbai. Settings and Design: The cross-sectional study was carried out from August to October 2012 on sample size of 385 school children, selected by systematic random sampling of class $\mathrm{VI}$ to $X$ of government-aided school. Materials and Methods: After a written-informed consent, students were interviewed by pre-tested, semi-structured questionnaire and then weight and height were recorded. Hemoglobin was estimated by cyanmethemoglobin method using a colorimeter. Data was analyzed by SPSS version 16 . Statistical Analysis Used: Proportion, Chi-square test, Co-relation Co-efficient and Unpaired t test. Results: Mean age was 12.9 years with SD of 1.5 years. Overall prevalence of anemia was $53.2 \%$ with prevalence in females and males $56.5 \%$ and $50 \%$, respectively. Proportion of mild, moderate and severe anemia was $21.6 \%$, $30.9 \%$ and $0.8 \%$, respectively. Age was significantly associated and negatively co-related with mean hemoglobin values with highest prevalence in age group of 15 to 19 years. Anemia was significantly associated with attainment of menarche. Practice of eating green leafy vegetables, groundnuts and egg was significantly higher in males as compared to females. Tiredness and palpitation were significantly higher in females as compared to males. Very few students (2.9\%) were aware about anemia. Only $75 \%$ of the students were willing to consume weekly iron and folic acid supplementation for a year. Conclusions: Both males and females are susceptible to anemia with highest prevalence in age group of 15 to 19 years. Awareness of anemia was very poor in school-going children.

Key words: Adolescents, anemia, WIFS program

\section{INTRODUCTION}

WHO estimates that around two billion people are anemic with approximately $50 \%$ of all anemia attributable to iron deficiency. ${ }^{[1]}$ India is among the countries with highest prevalence of anemia in the world. ${ }^{[2]}$ Anemia, a manifestation of under-nutrition and poor dietary intake of iron is a public health problem, not only among pregnant women, infants and young children but also among adolescents. ${ }^{[3]}$ Iron deficiency anemia in adolescent can negatively impact on growth, increase susceptibility to infection, and also impair mental development and learning ability. ${ }^{[4]}$ To combat anemia in adolescents, Government of India has decided to implement the Weekly Iron and Folic Acid Supplementation (WIFS) Programme. The program will cover school-going adolescent females and males from classes VI to XII enrolled in government/government aided/municipal schools through the platform of schools and out of school through the platform of Anganwadi centers..$^{[5]}$ The present study finds baseline prevalence and awareness of anemia in the school-going children in classes VI to X and willingness regarding WIFS program. The study also compares the frequency of iron-rich food consumption, symptoms of anemia and other causes of anemia between males and females. Moreover, socio-economic and nutritional variables are considered to find association with anemia. Most of the published literatures had focused on prevalence of anemia in school children but there is paucity of information on their dietary habits, awareness on anemia, willingness regarding WIFS for a year. Our study findings will thus, throw insight on anemia in adolescent, which can be a guiding tool for policy 
makers regarding WIFS program and IEC (Information, Education and Communication) messages.

\section{MATERIALS AND METHODS}

The cross-sectional study was carried out from August to October 2012 on the students of classes VI to X of governmentaided school, in Mumbai where Weekly Iron and Folic Acid Supplementation Programme (WIFS) has not yet started. Sample size was calculated by using the formula $\left\{(1.96)^{2} \times \mathrm{p} \times(1-\mathrm{p})\right\} /$ $(0.05)^{2}$. Considering the prevalence of anemia as $50 \%$, and $95 \%$ confidence interval, the target sample size was 384. Considering non-response rate as $20 \%$, the sample size was 461 . Proportionate sampling size for each class was calculated and also number of males and females from each class were again calculated by proportionate sampling size to have equal representation of males and females. Selection was done by systematic random technique. School authorities were informed about the purpose of the study and then written informed consent of the parent and the student were taken for the study. Out of 461 students, 76 students could not be interviewed due to unwillingness by parents or students for blood test, some were absent on the day of interview, or had left the school. Thus total 385 students were interviewed by pre-tested, semi-structured questionnaire regarding their parents' education, socio-economic status, etiology of anemia including dietary habits of consuming local staple iron rich sources, awareness about anemia and willingness for weekly iron and folic acid supplementation for a year. Later, weight and height were recorded and hemoglobin was estimated by cyan-methemoglobin method using a colorimeter. Known standards were run along with the test samples for maintaining quality control. Blood report with weight and height record was then handed to the students. Diagnosis and severity of anemia were done based on WHO guidelines. ${ }^{[6]}$ Nutritional status of the participants was assessed by using WHO new standard growth charts for Body Mass Index for Age. ${ }^{[7]}$ Data was analyzed by SPSS version 16.

\section{RESULTS}

Out of 461 students approached, 385 agreed to participate in the study giving a response rate of $83.51 \%$. Mean age of the participants was 12.9 years with SD of 1.5 years. According to Modified B. G. Prasad classification, $39.2 \%$ and $25.7 \%$ belonged to class III and class IV, respectively. Around $85.7 \%$ and $93.2 \%$ of mothers and fathers, respectively, were literate. Almost $70 \%$ of the parents studied till secondary schooling. Parents' education and socio-economic status was not significantly associated with anemia in school children. According to WHO new standard growth charts on Body Mass Index (BMI) for Age, around $17.6 \%$ and $13.5 \%$ of the students were thin and severely thin, respectively. The nutritional status (BMI for Age) was not significantly associated with anemia. Based on WHO cut-off value, overall prevalence of anemia was $53.2 \%$. Prevalence of anemia in females and males was $56.5 \%$ and $50 \%$, respectively. Proportion of mild, moderate and severe anemia was $21.6 \%, 30.9 \%$ and $0.8 \%$, respectively. Highest prevalence of anemia was in the age group of 15 to 19 years [Graph 1]. The prevalence of anemia amongst males in the age group of 9 to 11,12 to 14 and 15 to 19 years were $25.9 \%, 47.3 \%$ and $67.9 \%$, respectively. The prevalence of anemia amongst females in the age group of 9 to 11,12 to 14 and 15 to 19 years were $40.9 \%, 48.4 \%$ and $88.3 \%$, respectively.

Pearson Correlation $=-0.17 P$ value $<0.001$ (Significant)

Age was negatively co-related with mean hemoglobin values [Graph 2].The difference in mean hemoglobin between males and females in age group of 15 to 19 years was highly significant [Table

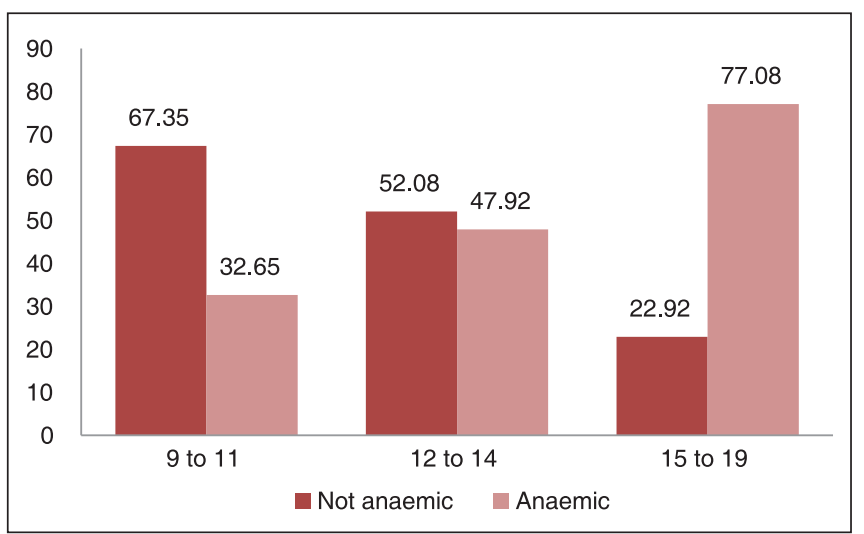

Graph 1: Prevalence in different age group

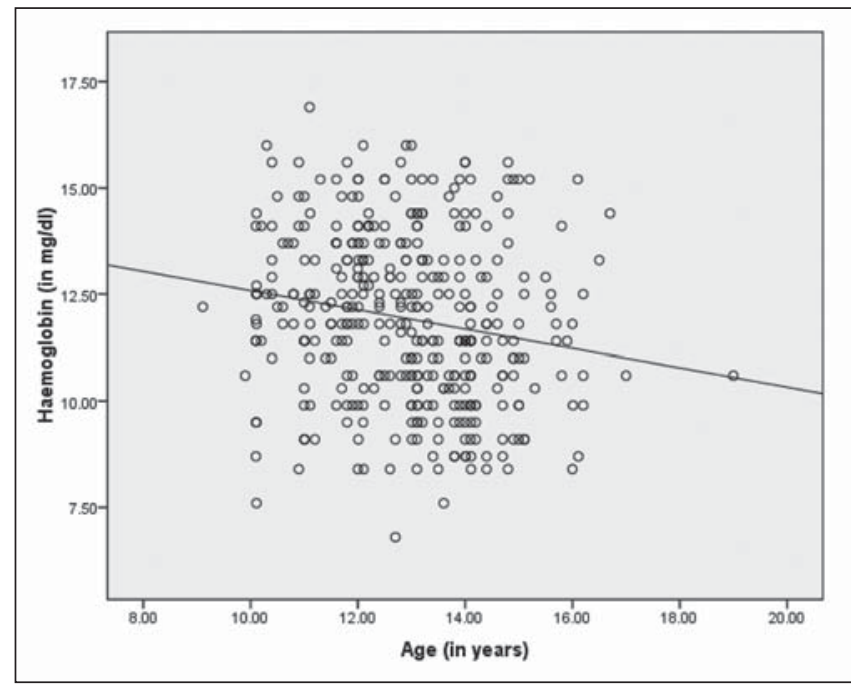

Graph 2: Co-relation of age with Hemoglobin

\begin{tabular}{|c|c|c|c|c|c|}
\hline \multirow{2}{*}{$\begin{array}{l}\text { Age in } \\
\text { years }\end{array}$} & \multicolumn{2}{|r|}{ Males } & \multicolumn{2}{|r|}{ Females } & \multirow[t]{2}{*}{$P$ value } \\
\hline & $n$ & Mean $\mathrm{Hb} \pm \mathrm{SD}$ & $n$ & Mean $\mathrm{Hb} \pm \mathrm{SD}$ & \\
\hline 9 to 11 & 27 & $12.41 \pm 1.77$ & 22 & $12.19 \pm 2.15$ & 0.25 \\
\hline 12 to 14 & 112 & $12.13 \pm 1.81$ & 128 & $12.02 \pm 2.05$ & 0.09 \\
\hline 15 to 19 & 53 & $11.95 \pm 2.14$ & 43 & $10.63 \pm 1.43$ & $0.00^{*}$ \\
\hline 9 to 19 & 192 & $12.12 \pm 1.89$ & 193 & $11.73 \pm 2.01$ & $0.05^{*}$ \\
\hline
\end{tabular}

Unpaired $t$ test *Significant 
1]. Anemia was significantly associated with attainment of menarche [Table 2]. Practice of eating iron-rich food especially green leafy vegetables, groundnuts and egg was significantly higher in males as compared to females [Table 3]. There was no statistical difference in the dietary habits of anemic and non-anemic adolescents. Passing of blood in stools was significantly high in females as compared to males. Symptoms of anemia such as tiredness and palpitation were significantly seen higher in females as compared to males [Table 4]. Only 60 students $(15.6 \%)$ had taken deworming treatment in the last six months. Out of 385 students, only 31 students $(8.1 \%)$ had consumed iron tablets in the last one month. Only $2.9 \%$ of the students (11 students) had heard about anemia and were aware about the causes and prevention of anemia. Out of 385 students, 149 males and 143 females ( $75 \%$ of the students) were willing to consume weekly iron and folic acid supplementation for a year.

\section{DISCUSSION}

Overall prevalence of anemia in school children was found to be $53.2 \%$, which is of severe public health magnitude according to

\begin{tabular}{|c|c|c|c|}
\hline Menarche & $n$ & Mean $\pm S D$ & $P$ value \\
\hline Attained menarche & 111 & $11.10 \pm 1.83$ & 0.00 \\
\hline Not attained menarche & 82 & $12.58 \pm 1.93$ & \\
\hline
\end{tabular}

Unpaired $t$ test *Significant
WHO. $^{[8]}$ Similar prevalence is reported by Sudhagandhi ${ }^{[9]}(52.88 \%)$ and by $\operatorname{Jain}^{[10]}(56.5 \%)$ in school-going children. Various studies ${ }^{[11-13]}$ has shown prevalence in school children around $41 \%$ to $51 \%$.

Our study shows that as age increases from 9 to 15 years, mean hemoglobin levels significantly goes on decreasing. Around $77.08 \%$ are anemic in the age group of 15 to 19 years. Thus priority should be given to this age group in WIFAS program. Our study was carried in VI to X class, with maximum age being 19 years. However, in practice to target 15 to 19 years, XI and XII class students i.e. junior colleges and school dropouts in the community have to be traced.

Further our study has shown significant difference in mean hemoglobin level between male and female $(12.12 \mathrm{v} / \mathrm{s} 11.73 \mathrm{~g} / \mathrm{dl})$. Prevalence of anemia in females and males was $56.5 \%$ and $50 \%$, respectively. According to NHFS-III (2005-06 survey), ${ }^{[14]}$ prevalence of anemia for female and males in age group of 15 to 19 years was $55.7 \%$ and $30.2 \%$, respectively. Similar findings were noted by Jain $\mathrm{T}$ and his colleagues ${ }^{[15]}$ in adolescent males with prevalence of $42.8 \%$. However, our study which represents adolescent school-going age group in urban slums of Mumbai shows much higher prevalence of $67.92 \%$ in males and $88.37 \%$ in females. This implies that females as well as males should be targeted for control of anemia.

Anemia was significantly associated with attainment of menarche. Kulkarni $^{[16]}$ also noted similar findings in their study.

\begin{tabular}{|c|c|c|c|c|c|c|}
\hline \multirow[t]{2}{*}{ Nutritional practice } & \multicolumn{2}{|c|}{ Males (n:192) } & \multicolumn{2}{|c|}{ Females (n:193) } & \multirow{2}{*}{$\begin{array}{l}\text { Chi-Square } \\
\text { Value }\end{array}$} & \multirow[t]{2}{*}{$P$ value } \\
\hline & Frequency & $\%$ & Frequency & $\%$ & & \\
\hline Eating green leafy vegetables at least thrice a week & 77 & 40.10 & 59 & 30.57 & 3.830 & $0.05^{*}$ \\
\hline Adding lemon in food & 55 & 28.65 & 65 & 33.68 & 1.136 & 0.286 \\
\hline Eating non-vegetarian food & 150 & 78.13 & 139 & 72.02 & 1.916 & 0.166 \\
\hline Eating germinated pulses at least thrice a week & 104 & 54.17 & 98 & 50.78 & 0.443 & 0.505 \\
\hline Eating jaggery-rich food & 33 & 17.19 & 25 & 12.95 & 1.349 & 0.246 \\
\hline Eating groundnut at least thrice a week & 80 & 41.67 & 53 & 27.46 & 8.590 & $0.003^{*}$ \\
\hline Eating ragi at least thrice a week & 13 & 6.77 & 16 & 8.29 & 0.319 & 0.572 \\
\hline Eating egg at least thrice a week & 61 & 31.77 & 38 & 19.69 & 7.355 & $0.007^{*}$ \\
\hline Do not drink tea & 23 & 11.98 & 26 & 13.47 & 0.193 & 0.660 \\
\hline
\end{tabular}

*Significant variables

\begin{tabular}{|c|c|c|c|c|c|c|}
\hline & \multicolumn{2}{|c|}{ Males ( $n: 192)$} & \multicolumn{2}{|c|}{ Females ( $n: 193)$} & \multirow[t]{2}{*}{ Chi-Square value } & \multirow[t]{2}{*}{$P$ value } \\
\hline & Frequency & $\%$ & Frequency & $\%$ & & \\
\hline \multicolumn{7}{|l|}{ Symptoms } \\
\hline Feel breathless & 28 & 14.58 & 42 & 21.76 & 3.334 & 0.06 \\
\hline Feel tired & 66 & 34.38 & 85 & 44.04 & 3.773 & $0.05^{*}$ \\
\hline Get palpitation & 62 & 32.29 & 82 & 42.49 & 4.273 & $0.03^{*}$ \\
\hline Loss of concentration & 45 & 23.44 & 38 & 19.69 & 0.800 & 0.37 \\
\hline \multicolumn{7}{|l|}{ Causes } \\
\hline Worms in stool & 24 & 12.50 & 14 & 7.25 & 2.978 & 0.84 \\
\hline Blood in stool & 5 & 2.60 & 14 & 7.25 & 4.435 & $0.03^{*}$ \\
\hline
\end{tabular}

*Significant variables 
Loss of blood in stools was also significantly higher in females as compared to males $(7.25 \% \mathrm{v} / \mathrm{s} 2.6 \%)$. It was also observed that students were shy when asked about passing of blood in stools, worm infestation or questions related to menstruation. Symptoms of anemia such as tiredness and palpitations were significantly higher in females as compared to males. It was observed that the students ignored those symptoms. The reason may be poor awareness about anemia $(2.9 \%)$ regarding its causes, prevention and treatment as observed in our study. Poor awareness regarding anemia was also noted by Mwanri ${ }^{[17]}$ in their study on school children. Surprisingly, only $75 \%$ of students were willing to consume WIFAS for a year.

Prevalence of eating iron-rich food was poor in both males and females. The dietary habits did not show any significant difference between anemic and non-anemic adolescents. However, certain foods like green leafy vegetables and eggs were more frequently eaten by males than females. It is difficult to say whether it was due to gender discrepancy as we have not asked history among the siblings of the same family. Only $15.6 \%$ and $8.1 \%$ of the total students had taken deworming treatment in the last six months and had consumed iron tablets in the last one month, respectively. Our finding of another community-based research project in the catchment area of the same school state that consumption of therapeutic and/or prophylactic iron folic acid supplementation by adolescent females is very poor $(11.9 \%)$ in urban slum area ${ }^{[18]}$ It also shows that $88 \%$ females who consumed IFA had received the same from school. Thus it is very important that schools should form the avenue to correct and prevent adolescent anemia in urban slums.

No significant relationship of anemia was observed with parents' education and socio-economic status. Verma and his colleagues ${ }^{[19]}$ in their study had also got the similar findings. In our study, nutritional status (BMI) was also not associated with anemia. This shows that all adolescent females and males, irrespective of their parents' education, socio-economic and nutritional status should be targeted for WIFAS supplementation.

Nutrition and Health Education sessions should be conducted in schools and in community to inculcate healthy eating habits. Adolescents should be informed about correct dietary practices for increasing iron intake. They should be informed about the causes, symptoms and ill effects of the anemia and importance of prophylactic/curative treatment for anemia. Also training should be given to them to understand the importance of each body part so that they don't feel shy. Apart from these, the health messages should include prevention of worm infestation, passing of blood in stools and personal hygiene. The rationale behind giving WIFAS should be told to parents and adolescent females and males, as there can be apprehension to consume tablets for a year.

\section{CONCLUSIONS}

Overall prevalence of anemia is $53.2 \%$ with highest prevalence in age group of 15 to 19 years. Both males and females are susceptible to anemia. Anemia is associated with attainment of menarche. Prevalence of passing blood in stools is higher in females. Overall frequency of consumption of iron-rich food is lower in males and females. Awareness of anemia is very poor in school-going children. Nutrition and Health Education session should be conducted in school with teachers and parents' involvement to raise awareness regarding anemia and WIFS program.

\section{ACKNOWLEDGMENT}

We are thankful to Mrs. Anjali Nimbhalkar (MSW), Mrs. Seema Shinde and Mr Muzawar (Lab Tech.), Mrs. Latika Agre and Ms. Shubhangi (Attendant) for their work in data collection. We are also grateful to the school authorities for their permission and students for participating in the study.

\section{REFERENCES}

1. WHO/Micronutrient deficiency. Available from:http://www.who.int/nutrition/ topics/ida/en/index.html.[Last accessed on 2013 Jun 4].

2. 7.11.1 anaemia - Ministry of Women and Child Development. Available from:http://wcd.nic.in/research/nti1947/7.11.1\%20anaemia\%20 deficiency.doc6.2.08\%20pr.pdf.[Last accessed on 2013 Jun 4].

3. Operational framework - Weekly Iron and Folic acid Supplementation Program for Adolescent. Available from:http://www.mohfw.nic.in/NRHM/ AH/WIFS/Operational\%20framework-\%20WIFS/Operational\%20 Framework\%20WIFS\%20MoHFW\%202012\%20.pdf.[Last accessed on 2013 Jun 4].

4. Jukes MC, Drake LJ, Bundy DA.School health, nutrition and education for all. Levelling the playing field. Wallingford, UK: CABI Publishing; 2008.

5. Press Information Bureau. Government of India. Available from: http:// pib.nic.in/newsite/erelease. aspx?relid=82516. [Last accessed on 2013 Jul 13].

6. Haemoglobin concentration for diagnosis of anaemia and assessment of severity.Available from: http://www.who.int/vmnis/indicators/haemoglobin. pdf.[Last accessed on 2013 Jun 4].

7. WHO-Growth reference data for 5-19 years. Available from:http://www. who.int/growthref/en/ [Last accessed on 2013 Jul 13].

8. Iron deficiency anaemia - Assessment, Prevention and Control - A guide for Program Managers. Available from:http://www.who.int/nutrition/ publications/micronutrients/anaemia_iron_deficiency/WHO_NHD_01.3/ en/index.html.[Last accessed on 2013 Jun 4].

9. Sudhagandhi B, Sundaresan S, Ebenezer W, PremaA.Prevalence of anaemia in the school children of Kattankulathur, Tamil Nadu, India.Int J Nutr Pharmacol Neurol Dis 2011;1:184.

10. Jain V, Jain N. Prevalence of anaemia in school children. Med Pract Rev 2012;3:1-4.

11. Gomber S, Bhawna, Madan N, Lal A, Kela K. Prevalence and etiology of nutritional anaemia among school children of urban slums. Indian J Med Res 2003;118:167-71

12. Verma M, Chhatwal J, Kaur G.Prevalence of anemia among urban school children of Punjab. Indian Pediatr 1998;35:1181-6.

13. Hall A, Bobrow E, Brooker S, Jukes M, Nokes K, Lambo J,et al. anaemia in school children in eight countries in Africa and Asia. Public Health Nutr 2001;4:749-56.

14. Parasuraman S, Kishor S, singh SK, Vaidehi Y. 2009. A Profile of Youth in India. National Family Health Survey (NFHS-3), India, 2005-06. Mumbai: International Institute for Population Sciences; Calverton, Maryland, USA: ICF Macro.Available from: http://www.rchiips.org/ NFHS/youth_report_for_website_18sep09.pdf[Last accessed on 2013 Jun 4].

15. Jain T, Chopra H, Mohan Y, Rao S. Prevalence of anaemia ant its relation to socio-demographic factors: Cross-sectional study among adolescent boys in urban Meerut, India. Biol Med 2011;3:1-5. 
16. Kulkarni M, Durge $P$, Kasturwar N. Prevalence of anaemia among adolescent girls in an urban slum. Natl J Community Med 2012;3:108-111

17. Mwanri L, Worsley A, Masika J. School and anaemia prevention: Current reality and opportunities - a Tanzanian case study. Health PromotInt 2001;16:321-31.

18. Kowli S, Dyavarishetty P.Understanding the Community`s Perceptions: Improving the ICDS programme for Adolescent Girls "Kishori Shakti Yojana. Report of the Research Project funded by ICMR, File No 6/11/17/2010-SBR.
19. Verma A, Rawal V, Kumar D, Chauhan J. Factors influencing anaemia among girls of school going age (6-18 years) from the slums of Ahmadabad city. Indian J Com Med 2004;29:25-6.

How to cite this article: Sabale RV, Kowli SS, Chowdary PH. Prevalence of anemia and its determinants in urban school-going children of Mumbai. Int J Med Public Health 2013;3:325-9.

Source of Support: Nil, Conflict of Interest: None declared. 